\title{
SEM-EDS and X-ray micro computed tomography studies of skeletal surface pattern and body structure in the freshwater sponge Spongilla lacustris collected from Goczalkowice reservoir habit (Southern Poland)
}

\author{
Jagna Karcz ${ }^{1}$, Andrzej Woznica ${ }^{2}$, Marcin Binkowski ${ }^{3}$, Malgorzata Klonowska-Olejnik ${ }^{4}$, \\ Tytus Bernas ${ }^{5}$, Jerzy Karczewski ${ }^{6}$, Pawel Migula ${ }^{7}$
}

${ }^{1}$ Laboratory of Scanning Electron Microscopy, Faculty of Biology and Environmental Protection, University of Silesia, Katowice, Poland

${ }^{2}$ Department of Biochemistry, Faculty of Biology and Environmental Protection, University of Silesia, Katowice, Poland

${ }^{3}$ Department of Biomedical Computer Systems, Institute of Computer Science, University of Silesia, Sosnowiec, Poland

${ }^{4}$ Research \& Science Innovation Centre, Lublin, Poland

${ }^{5}$ Nencki Institute of Experimental Biology, Polish Academy of Sciences, Laboratory of Imaging Tissue Structure and Function, Warszawa, Poland

${ }^{6}$ Department of Biophysics and Plants Morphogenesis, Faculty of Biology and Environmental Protection, University of Silesia, Katowice, Poland

${ }^{7}$ Department of Animal Physiology and Ecotoxicology, Faculty of Biology and Environmental Protection, University of Silesia, Katowice, Poland

\footnotetext{
Abstract

Introduction. Freshwater sponges are common animals of most aquatic ecosystems. They feed by filtering small particles from the water, and so are thought to be sensitive indicators of pollution. Sponges are strongly associated with the abiotic environment and are therefore used as bioindicators for monitoring of water quality in water habitats. Among the freshwater sponges, Spongilla lacustris is one of the classic models used to study evolution, gene regulation, development, physiology and structural biology in animal water systems. It is also important in diagnostic of aquatic environments. The aim of this study was to characterize and visualize three-dimensional architecture of sponge body and measure skeleton elements of S. lacustris from Goczalkowice reservoir for identification purposes.

Material and methods. The scanning electron microscopy with an energy dispersive X-ray microanalysis (SEM-EDS) and X-ray micro computed tomography (micro-CT) were used to provide non-invasive visualization of the three-dimensional architecture of Spongilla lacustris body.
} 
Results. We showed that sponge skeleton was not homogeneous in composition and comprised several forms of skeleton organization. Ectosomal skeleton occurred as spicular brushes at apices of primary fibres with cementing spongin material. Choanosomal skeletal architecture was alveolate with pauci- to multispicular primary fibres connected by paucispicular transverse fibres, made by megascleres embedded in a scanty spongin matrix both in the choanosome and at the sponge surface. In contrast, microscleres were irregularly scattered in choanosome and skeletal surface. Furthermore, SEM-EDS studies showed that the distribution of silica in megascleres and microscleres was observed along the spicules and sponge surface areas.

Conclusions. In conclusion, we showed that the combination of SEM-EDS and micro-CT microscopy techniques allowed obtaining a complete picture of the sponge spatial architecture. (Folia Histochemica et Cytobiologica 2015, Vol. 53, No. 1, 88-95)

Key words: high-resolution scanning electron microscopy; energy dispersive X-ray spectroscopy; X-ray micro computed tomography; sponge; skeletal architecture

\section{Introduction}

Sponges represent a natural resource for their functional role in natural processes of water purification in freshwater ecosystems. Freshwater sponges (Demospongiae) are an important component of aquatic ecosystem filtering particles of a smaller size range than other benthic invertebrates. Therefore, the study of freshwater sponges has become increasingly popular as more is known about their ability to filter large volumes of water together with their importance as bioindicators in diagnostic of aquatic environments [1-3]. Moreover, sponges are strongly associated with the abiotic environment and are therefore very sensitive to environmental stress. So, this species is the good indicator of water quality [4].

In our study, the use of living organisms as bioindicators for monitoring of water quality in water reservoirs was one of the aims of the project "Integrated system supporting management and protection of water reservoir" (ZiZOZap, project no 01.01.0-24-078/09), realized in the period of 2010-2014 under the Operational Program Innovative Economy. Goczalkowice Water Reservoir has been used as the model. Among the organisms tested, freshwater sponge Spongilla lacustris was the subject of our investigation.

The aforementioned freshwater sponge Spongilla lacustris is classified into the phylum Porifera, class Demospongiae, order Haplosclerida, suborder Spongillina, family Spongillidae, based on the nature of the mineral skeleton. It is one of the most common and widespread freshwater sponges in the northern hemisphere [5]. It is also a classical model organism used to study evolution, gene regulation, development, physiology and structural biology in non-bilaterian animal systems [6-8].

The data on the general sponge morphology of S. lacustris forms have been summarized [9-12]. In these papers the phenotypic characterization of sponge body structures has been described (e.g., surface morphology, shape and ornamentation of spicules, gemmule structure. Recently, spicules classification and their chemical content were described [13, 14]. It was noted that chitin is an important structural component within the siliceous skeletal fibres of the freshwater sponge $S$. lacustris. On the other hand, the spatial morphology of sponge body and three-dimensional skeletal architecture of S. lacustris was not documented. This lacuna has prompted the present investigation. Here, we applied a combination of the SEM-EDS and X-ray micro computed tomography (micro-CT) to visualize spatial architecture of S. lacustris skeleton. The combination of these microscopic techniques allowed obtaining a complete picture of the sponge body structure and skeleton organization. Furthermore, our study of S. lacustris from Goczalkowice reservoir can contribute to increase knowledge on the freshwater sponges' distribution in Poland.

\section{Material and methods}

Collection of samples. The sponge material was collected in June 2013 during biological monitoring in the Goczalkowice reservoir (Southern Poland). Sponge colony occurred on concrete stairs at the port of reservoir. The specimens were immediately stored in containers with Goczalkowice water and transported to the Scanning Electron Microscopy Laboratory (University of Silesia, Katowice). After collection the sponges were cut into small pieces (5-10 mm thick) with razor blades and fixed. They were subsequently prepared for scanning electron microscopy and X-ray micro-CT.

The collected specimens were identified as Spongilla lacustris based on general architecture of surface body and skeletal elements (megascleres and microscleres) morphology and compared to published descriptions $[9,10]$.

Scanning electron microscopy and energy dispersive X-ray microanalysis (SEM-EDS). For SEM, two different methods 
of sponge preparation were used: chemical fixation with critical point drying (CPD) and lyophilisation. Part of sponge material were fixed in $3 \%$ glutaraldehyde in $0.1 \mathrm{M}$ phosphate buffer and postfixed in $1 \%$ osmium tetroxide. These were dehydrated in the ascending ethanol series, critical-point dried in Pelco CPD2 apparatus (Ted Pella Inc., Redding, CA, USA), mounted on an aluminium stubs with double-sided adhesive carbon tape, and gold sputtered in Pelco SC-6 sputter coater (Ted Pella Inc.) to investigate skeletal architecture. The rest sponge specimens were rapidly frozen by liquid nitrogen and lyophilised in the Lyophilisator Christ Alpha 4 L (Martin Christ Gefriertrocknungsanlagen GmbH, Osterode am Harz, Germany), temperature $-50^{\circ} \mathrm{C}$, pressure $4 \mathrm{~Pa}$, and then sputter-coated with gold. All specimens were imaged by the Hitachi SU8010 field emission scanning electron microscope FESEM (Hitachi High-Technologies Corporation, Tokyo, Japan), at $10 \mathrm{kV}$ accelerating voltage with secondary electron detector (ESD), and working distance (WD) of 10-30 mm. To determine whether there is infraspecific variation in sponge body structure 10 specimens (pieces 5-10 mm thick) from each dried sponge material were examined in SEM.

Energy dispersive X-ray microanalysis (EDS) was used to identify the elemental composition of skeletal spicules. SEM X-ray microanalysis uses the characteristic X-rays generated from an electron-bombarded sample to identify elemental constituents that comprise the sample. This technique generates a spectrum in which the peaks correspond to specific X-ray lines, enabling the easy identification of elements present in the sample. For X-ray microanalysis, 10 specimens (fragments about 5-10 mm thick) of lyophilised (freeze-dried) sponge material were mounted on specimen aluminium stubs and coated with gold. The specimens were examined in a Hitachi SU8010 field emission scanning electron microscope with a Thermo Scientific Noran System 7 energy dispersive spectrometer (Thermo Fisher Scientific, Madison, WI, USA). Background and element-specific peak spectra were analysed using the program NSS3 X-ray Microanalysis (Thermo Fisher Scientific). A $10-\mathrm{kV}$ acceleration was used for the SEM-mode microanalysis. The gain rate was adjusted to $600-1000$ counts $\mathrm{s}^{-1}$, and the acquisition time was $100 \mathrm{~s}$. Analyses were performed at $2500 \times$ magnification, producing spectra for small areas $(5.0$ and $10.0 \mu \mathrm{m})$ along the entire length of the spicules, including spicule tips and spines. We analysed about 3-10 basic points in each spicule. The corresponding Si signals were examined in the spectra. The SEM images and corresponding EDS spectra were taken for all specimens and one typical image and selected spectra of spicules are given in Figure 2.

X-ray micro computed tomography (micro-CT). X-ray micro computed tomography scanner (v|tome |x s, GE Sensing \& Inspection Technologies, Phoenix|x-ray, Wunstorf, Germany) was used for non-destructive imaging the samples of spongy body. Lyophilised and gold sputtered sponge specimens were placed into plastic tube (universal $20 \mathrm{~mL}$ ) and located on the rotary table in the scanner chamber. The tube with reflection tungsten target was used and scanning settings $($ Voltage $=60 \mathrm{kV}$, current $=140 \mu \mathrm{A}$, no filter, timing $=500 \mathrm{~ms}$, number of projections $=2000$, average $=2$, skip $=1$ ) were adjusted to distinguish the details of soft tissue in samples and maintained power (8.4 Watts) lower than voxel size $\left(9.238 \mu \mathrm{m}^{3}\right)$. Therefore spatial resolution of imaging was predominated by voxel size which was higher than tube spot size. The total scanning time was equal to 36 minutes. The whole process of the image acquisition was controlled by manufacturer software (Datos 2.0, GE Sensing $\&$ Inspection Technologies, Phoenix $\mid \mathrm{x}$-ray), which was also used to reconstruction process.

\section{Results}

The sponge morphology and spicule framework of Spongilla lacustris are presented in Figures 1-3. Body shape, spicules and skeletal fibres of the studied sponge body allowed the certain ascription of $S$. lacustris. In general view, sponge colonies were bushy shaped, with many branched finger-like projections and a massive base (30-60 cm high). Gemmules occurred sporadically throughout the sponge body. They were single, free and scattered in the skeletal network, or restricted to the sponge base in groups, or strictly adherent to the substratum. They had very few gemmoscleres or without of them.

SEM images of cross-sectioned sponge body showed the presence of two types of spicules: megascleres, which made up the primary framework of a sponge skeleton and microscleres, which are spicules of smaller sizes, scattered both in the sponge mesohyl and at the sponge surface (Figure 1A-D). Megascleres were embedded in the spongin matrix both in the internal layers (choanosome) and at the sponge surface (ectosome). They were irregularly dispersed in confused fibres, bound together by spongin material. Sponge surface membrane is supported by end of these fibres, which crossed membrane, ending at surface in a fine hispidation (Figure 1A, C). Microscleres were packed between multispicular megasclere fibres, supporting the soft parts of choanosome and skeletal surface (Figure 1B, D). Both megascleres and microscleres were sharply pointed at both ends and slightly curved. Megascleres were smooth (Figure 1E), while microscleres were covered with small spines, regularly distributed along the entire length and microspinosity on spines giving them an asterose shape (Figure 1F). These spicules formed the irregularly reticulate type of skeletal architecture according to their size and distribution. In S. lacustris, this type of reticulation 

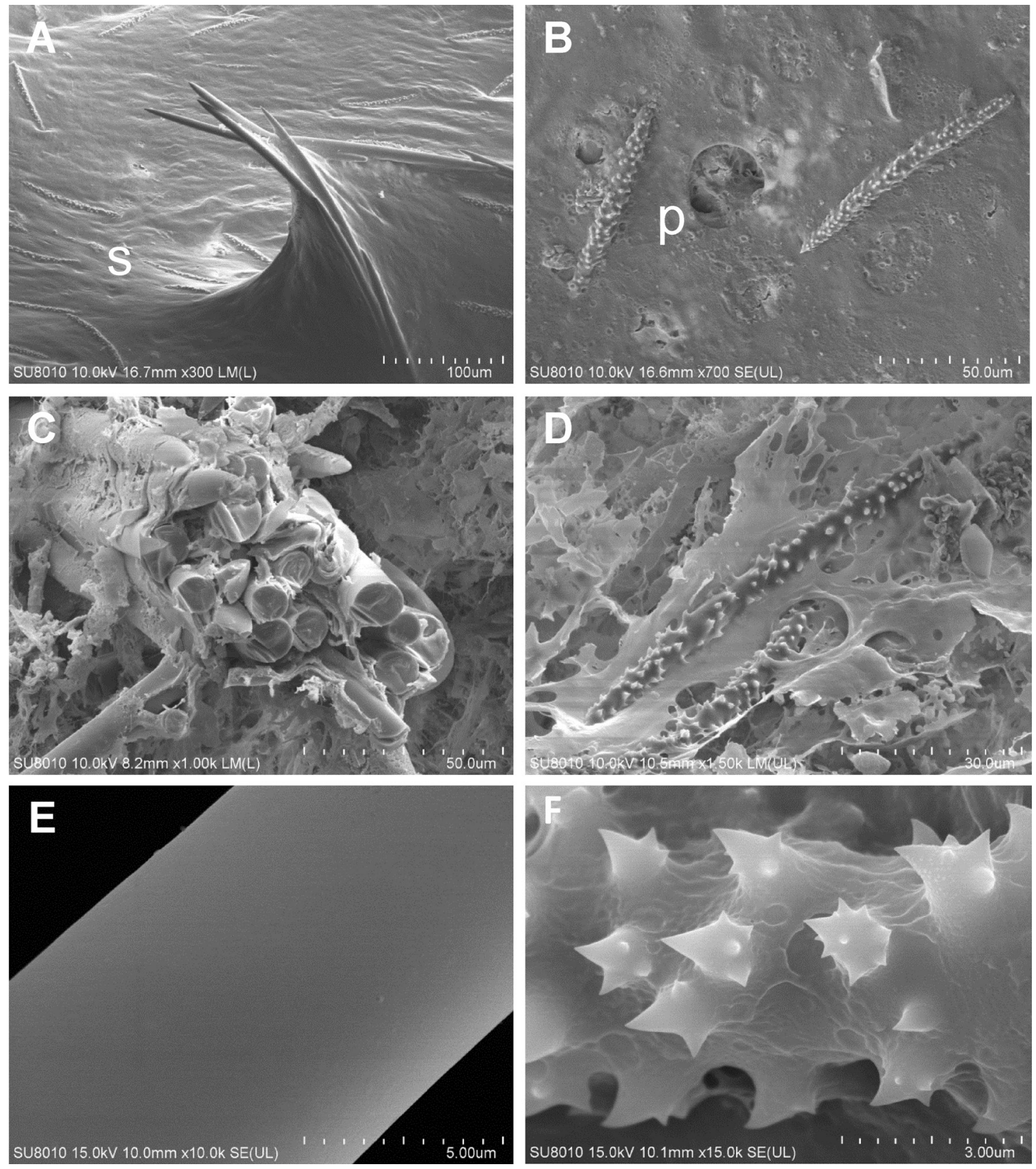

Figure 1. Representative SEM images of sponge morphology and skeleton characteristics of Spongilla lacustris. A. Sponge surface (top view) showing protruding jutting spicules (megascleres). Megascleres are bound together and to the substratum by sponging deposits (s); B. Part of the ectosomal sponge surface with irregularly distributed microscleres and small faintly distinguished dermal pores (p); C. Fractured multispicular choanosomal fibre composed of several nonlaminated megascleres; D. Internal view of sponge body showing microscleres embedded in choanosomal spongin matrix (microscleres irregularly arranged in the sponge mesohyl); E. Detailed structure of megasclere showing smooth surface pattern; F. Microsclere showing asterose shape of spine

is characterized by branching and anastomosing of megasclere fibres, microscleres do not seem involved in the main skeletal network.

We also analysed silica content in spicules, both in mega- and microscleres by SEM-Energy Dispersive microanalysis (EDS) method. The example of SEM
$\mathrm{X}$-ray images which mapped the location of silica $(\mathrm{Si})$, oxygen $(\mathrm{O})$ and carbonate $(\mathrm{C})$ elements in spicules and sponge surface areas were showed in Figure 2A-F. In megascleres (Figure 2A, B) and microscleres (Figure 2C-F) the distribution of silica was observed along the spicules. The results from SEM-EDS indi- 

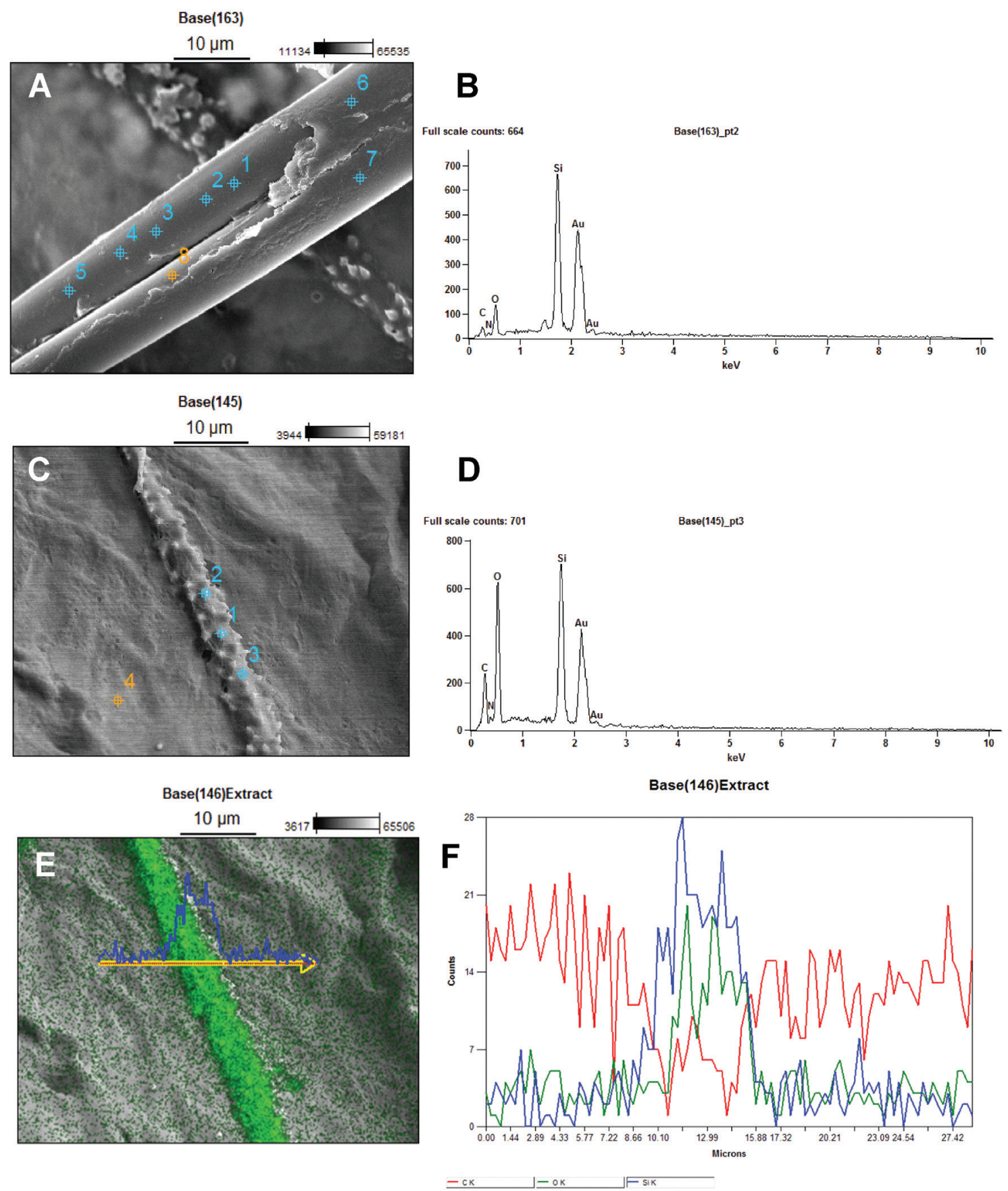

Figure 2. Representative SEM-EDS images of Spongilla lacustris spicules. A, B. Choanosomal fused together megascleres and EDX spectrum of the silica (Si) content; C-F. Ectosomal microscleres and corresponding EDX spectra from microscleres presenting the location of Si (blue), O (green), C (red)

cated that, the concentration and distribution of $\mathrm{Si}$ element were characterized the spicules of S. lacustris.

Additional characterization of the studied sponge colony was performed using X-ray micro-CT(Figure 3). The X-ray CT images of longitudinal-sectioned adult sponge body showed that internal choanosomal skeleton formed pauci- to multispicular primary fibres (tracts) connected by paucispicular transverse fibres with irregular to regular meshes, occasionally with large alveolate cavities; where spongin material was mostly sparse (Figure 3A, B). Multispicular fibres were thick, radiated from the base of sponge attachment, and ended with fine points, whereas paucispicular fibres were more delicate and formed 

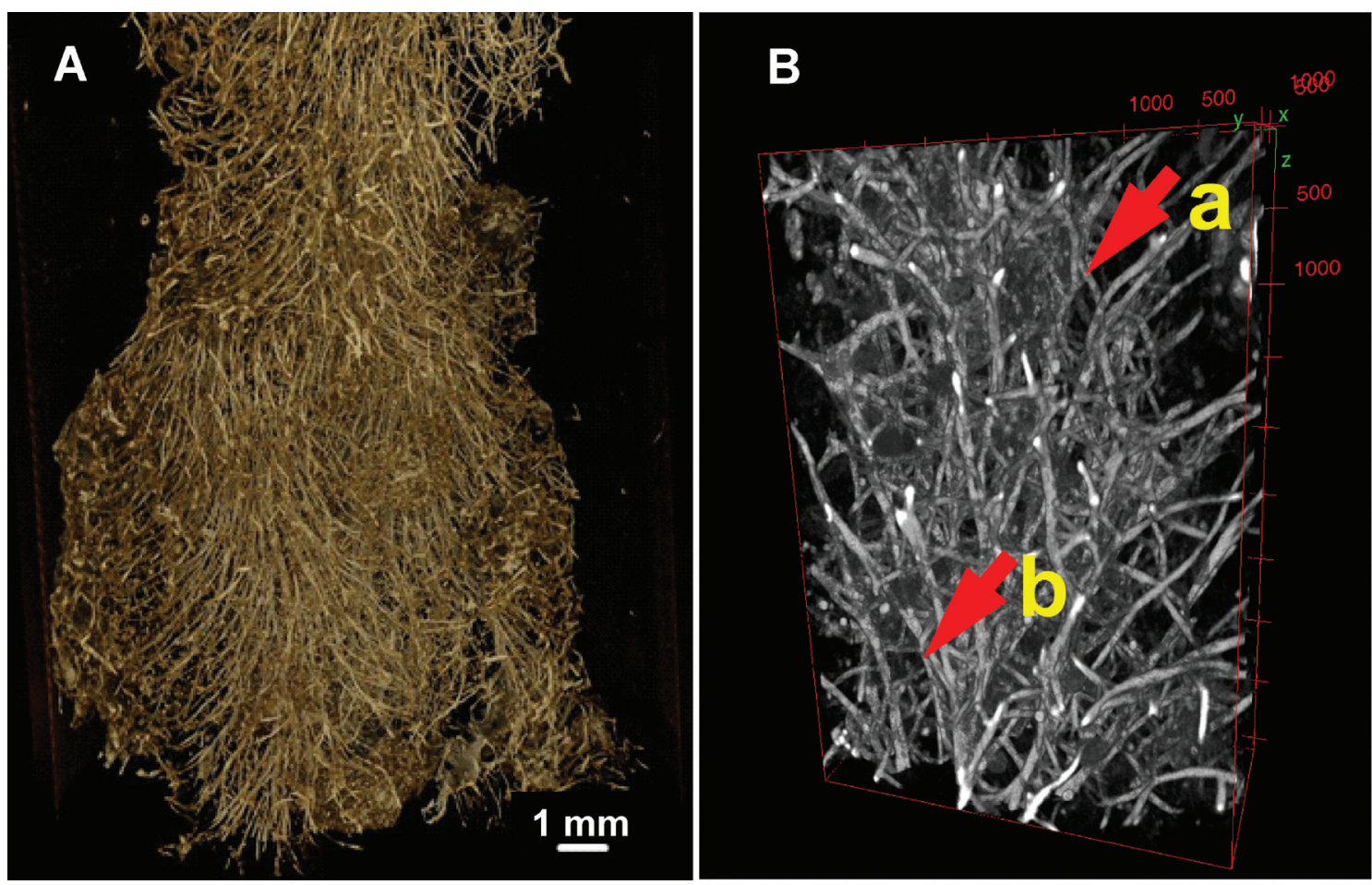

Figure 3. Representative X-ray CT images of Spongilla lacustris sponge skeleton. A, B. Longitudinal sections showing a complex skeletal arrangement with paucispicular megasclere fibres (a) and multispicular megasclere fibres (b)

branched secondary fibres, which connected the mulitispicular tracts. The principal fibres had a rough exterior and contained spongin material. These fibres were usually radial to axial arranged. Such a spatial arrangement of the skeleton spicules allows sponges to grow upwards and facilitate water exchange with minimal metabolic cost.

\section{Discussion}

In this study, we presented the first detailed description with clear SEM-EDS images and X-ray micro-CT visualization of the adult freshwater sponge Spongilla lacustris from Goczalkowice reservoir habit. SEM-EDS allowed observing external and internal pattern of sponge skeleton at the large area with excellent resolution of the topographic features and elemental composition of sponge spicules. The $\mathrm{X}$-ray micro-CT was used to provide non-invasive 3D visualization of large volumes of the sponge body. These observations gave comprehensive information about spatial architecture of sponge body, skeleton configuration and spicules micro-ornamentation. In analysed sponge body, siliceous spicules formed the irregularly reticulate type of skeletal architecture. This type of reticulation was characterized by the presence of pauci- to multispicular choanosomal fibres, made by megascleres embedded in a scanty spongin matrix both in the choanosome and at the sponge surface. In contrast, microscleres were irregularly scattered in choanosome and skeletal surface. Our SEM results were in accordance with the observations of the previous study, which reported that the identification of freshwater sponges has traditionally been based on their morphological characters, among which the skeletal architecture and spicule ornamentation have been of particular importance [15-17].

We also observed the sponge growth form as paralectotype with sporadically occurred gemmoscleres. It is noted that gemmulation process may be caused by endogenous factors and specific environmental conditions (physical and chemical parameters of water) $[18,19]$. Some studies have demonstrated the morphological diversity of $S$. lacustris growth forms from different water habits, where body shape was appeared as encrusting to digitated, to branched and arborescent according to the life cycle stage and environmental conditions. The sponge growth habit may also reflect the underlying skeletal arrangement. Thus, environmental factors may control the appearance of sponge growth form and skeletal frameworks [20,21].

Recent studies revealed that chitin is an important structural component within the siliceous skeletal fibres of the marine and freshwater sponges, including 
S. lacustris [14]. It is a fibrous substance consisting of polysaccharides and forming the major constituent within the skeletal fibres. Thus, the skeleton of the sponge consists of siliceous spicules embedded into a fibrous organic matrix made from chitin and spongin. Such a chemical composition enhances the mechanical properties of the sponge skeleton and can provide support for a large internal surface area, as well as stability under flow currents.

Our another major imaging method of skeletal structure was X-ray micro-CT. This technique is widely used for imaging three-dimensional internal structures and it is based on the difference in radiation absorption by different tissues [22-24].

In this study, we used micro-CT for the first time to observe spatial structure of sponge skeleton. This technique allowed detailed virtual reconstructions of the morphology and anatomy of adult sponge body and subsequent interactive manipulation (e.g. rotation, virtual dissection). Of course, SEM is superior in terms of resolution, but micro-CT provides spatial information on the relationship between single selected spicules and the total skeleton. Micro-CT technique also reduces the need for the destructive sampling of valuable type specimens, since small specimens can be imaged completely and parts of larger specimens can be returned to the collection after scanning. Thus, this method complements light and scanning electron microscopy and represents a valuable extension to the sponge taxonomy since it allows morphometric measurements in three-dimensional projection [25].

In conclusion, the present study demonstrates that the combination of SEM with energy dispersive $\mathrm{X}$-ray microanalysis (SEM-EDS) and X-ray micro-CT techniques allowed obtaining a complete picture of the sponge structure and skeleton organization. $S$. lacustris secrete siliceous elements, which can subsequently fuse, interlock with each other, or form three-dimensional structures connected by spongin. This form of the spatial structure of the skeleton allows sponges to grow upwards and facilitate water exchange with minimal metabolic cost. Understanding the structure and chemical composition of the sponge skeleton may prove to be a novel model for applications in modern materials science and biotechnology. To our best knowledge, our study presents the first SEM-EDS documentation as well as X-ray computed tomography images of spicules spatial pattern of freshwater sponge $S$. lacustris reported here.

\section{References}

1. Manconi R, Pronzato R. Spongillids of Mediterranean Islands. In: Van Soest RWM, Van Kempen TMG, Braekman JC, eds. Sponges in time and space. Rotterdam: Balkema; 1994:333-340.
2. Dröscher I, Waringer J. Abundance and microhabitats of freshwater sponges (Spongillidae) in a Danubean floodplain in Austria. Freshwater Biol. 2007;52:998-1008. doi: 10.1111/j.1365-2427.2007.01747.x.

3. Evans KL, Kitting ChL. Documentation and identification of the one known freshwater sponge discovered in the California Delta. Open Mar Biol J. 2010;4:82-86. doi: 10.2174/1874450801004010082.

4. de Ronde CEJ, Stoffers P, Garbe-Schonberg D et al. Discovery of active hydrothermal venting in Lake Taupo, New Zealand.J Volcan Geotherm Res. 2002;115:257-275. doi:10.1016/ /S0377-0273(01)00332-8.

5. Manconi R, Pronzato R. Rediscovery of the type material of Spongilla lacustris (L., 1759) in the Linnean herbarium. Ital J Zool. 2000;67:89-92. doi: 10.1080/11250000009356300.

6. Borchiellini C, Chombard C, Lafay B, Boury-Esnault N. Molecular systematics of sponges (Porifera). Hydrobiologia. 2000;420:15-27. doi: 10.1023/A:1003996517083.

7. Boury-Esnault N. Systematics and evolution of Demospongiae. Can J Zool. 2006;84:205-224. doi: 10.1139/Z06-003.

8. Van Soest RWM, Boury-Esnault N, Vacelet J et al. Global diversity of sponges (Porifera). PLOS ONE. 2012;7:e35105. doi:10.1371/journal.pone.0035105.

9. Manconi R, Pronzato R. Suborder Spongillina subord. nov.: freshwater sponges. In: Hooper JNA, Van Soest RWM, eds. Systema Porifera: A guide to the classification of sponges. New York: Kluwer Academic/Plenum Publications; 2002: 921-1019.

10. Manconi R, Pronzato R. Global diversity of sponges (Porifera: Spongillina) in freshwater. Hydrobiologia. 2008;595:27-33. doi: 10.1007/s10750-007-9000-x.

11. Weaver JC, Pietrasanta LI, Hedin N, Chmelka BF, Hansma PK, Morse DE. Nanostructural features of demosponge biosilica. J Struct Biol. 2003;144:271-281. doi:10.1016/ /j.jsb.2003.09.031.

12. Sandford F. Physical and chemical analysis of the siliceous skeletons in six sponges of two groups (Demospongiae and Hexactinellida). Microsc Res Tech. 2003;62:336-355. doi: 10.1002/jemt.10400.

13. Uriz M-J. Mineral skeletogenesis in sponges. Can J Zool. 2006;84:322-356. doi: 10.1139/Z06-032.

14. Ehrlich H, Kaluzhnaya OV, Brunner E et al. Identification and first insights into the structure and biosynthesis of chitin from the freshwater sponge Spongilla lacustris. J Struct Biol. 2013;183:474-483. doi:10.1016/j.jsb.2013.06.015.

15. Økland K, Økland J. Freshwater sponges (Porifera: Spongillidae) of Norway: distribution and ecology. Hydrobiologia. 1996;330:1-30. doi: 10.1007/BF00020819.

16. Uriz M-J, Turon X, Becerro M, Agell G. Siliceous spicules and skeleton frameworks in sponges: origin, diversity, ultrastructural patterns and biological functions. Microsc Res Tech. 2003;62:279-299. doi: 10.1002/jemt.10395.

17. Lopp A, Reintamm T, Vallmann K et al. Molecular identification, characterization and distribution of freshwater sponges (Porifera: Spongillidae) in Estonia. Fundam Appl Limnol. 2007;168:93-103. doi: 10.1127/1863-9135/2007/0168-0093.

18. Wulff JL. Ecological interactions of marine sponges. Can J Zool. 2006;84:146-166. doi:10.1139/Z06-019.

19. Manconi R, Pronzato R. Gemmules as a key structure for the adaptive radiation of freshwater sponges: a morphofunctional and biogeographical study. In: Custódio MR, Lôbo-Hajdu G, Hajdu E, Muricy G, eds. Porifera Research: Biodiversity, Innovation and Sustainability. Rio de Janeiro: Série Livros 28, Museu Nacional; 2007:61-77. 
20. Manconi R, Pronzato R. Life cycle of Spongilla lacustris (Porifera, Spongillidae): a cue for environment-dependent phenotype. Hydrobiologia. 1991;220:155-160. doi: 10.1007/ /BF00006548.

21. Volkmer-Ribeiro C, de Souza Machado V. Freshwater sponges (Porifera, Demospongiae) indicators of some coastal habitats in South America: redescriptions and key to identification. Iheringia Sér Zool. 2007;97:157-167. doi: 10.1590/ /s0073-47212007000200005.

22. Stuppy WH, Maisano JA, Colbert MW, Rudall PJ, Rowe TB. Three-dimensional analysis of plant structure using high-resolution X-ray computer tomography. Trends Plant Sci. 2003;8:2-6. doi:10.1016/S1360-1385(02)00004-3.
23. Metscher BD. Micro CT for developmental biology: a versatile tool for high-contrast 3D imaging at histological resolutions. Dev Dynam. 2009;238:632-640. doi: 10.1002/dvdy. 21857.

24. Faulwetter S, Dailianis T, Vasileiadou A, Arvanitidis Ch. Contrast enhancing techniques for the application of micro-CT in marine biodiversity studies. Microsc Anal. 2013;27:4-7. doi: 10.3897/zookeys.263.4261.

25. Nickel M, Donath T, Schweikert M, Beckmann F. Functional morphology of Tethya species (Porifera): 1. Quantitative 3D-analysis of Tethya wilhelma by synchrotron radiation based X-ray microtomography. Zoomorphology. 2006;125:209-223. doi: 10.1007/s00435-006-0021-1.

Submitted: 17 October, 2014

Accepted after reviews: 11 February, 2015

Available as AoP: 13 February, 2015 